\title{
Mapping Discourse and Agency in a Refugee Context: An Interview With Reem Doukmak
}

\author{
Reem Doukmak \\ University of Warwick, Applied Linguistics \\ R.Doukmak@warwick.ac.uk
}

\begin{abstract}
Reem Doukmak was born in Syria and studied English literature at al-Baath University. In 2007 she completed her Master's degree at the University of Warwick. With the help of CARA she continued her studies at Warwick where she is now starting her academic career. Her work investigates how the right pedagogic interventions can help children in refugee camps. The use of drama plays a key role in her research and feeds into broader questions surrounding self-representation and agency. These are among the vital issues The Journal of Interrupted Studies has also sought to explore. We were lucky to engage Reem on her research and its implications for addressing the problematic discourses that surround refugees and yet neglect to include their voice.
\end{abstract}

\section{Keywords}

refugee studies - linguistics - pedagogy - drama - discourse analysis - Syria - Turkey

TJIs: Can you give us an overview of your $\mathrm{PhD}$ project on refugee agency and the discourses surrounding refugees?

Reem Doukmak: My PhD project examines the educational needs and experiences of Syrian teachers and students in a refugee border context. The study is illustrated with a case study framework combining ethnography and action research. I introduce drama as an innovative teaching method to the English classroom and looked at how refugee teachers engaged with research inter-

(C) REEM DOUKMAK, 2019 | DOI:10.1163/25430149-00201005

This is an open access article distributed under the terms of the prevailing CC-BY-NC License at the time of publication. 
ventions and the positive outcomes of drama on the learning experiences of students. One of the research questions centres around the role of refugee discourse on refugee agency and engagement with research interventions. At the same time, refugees' voices reveal the incongruity of what the reality of the Syrian crisis means for them in contrast to media and political representations.

\begin{abstract}
Having left Syria and now working in refugee studies, you have an important relationship with the people and situations you are studying. Do you think there is a particular role for academics who are themselves affected by forced migration? If so, how has this shaped your academic practice when looking at these issues?
\end{abstract}

As a Syrian, I embarked on this research with an obligation to help my fellow Syrians who have been displaced by the war. I started to connect with teachers in Turkey, which is the largest host of Syrian refugees in the world. In the field, I was more than a researcher. I was met with high expectations to solve educational and life problems. I took on many roles including trainer, instructor, educational adviser and humanitarian actor among others. My fieldwork experiences have largely shaped my understanding of the local and global dynamics of the refugee crisis and the interplay between researcher identity, and the researched context and subjects.

How should we map out the concept of agency with respect to discourse in the present situation?

The term agency describes the largest refugee NGO: UNHCR which supports refugees throughout the world. Although the term is taken to imply supporting refugees, it highlights them as victims worthy of assistance and empathy. On the other hand, the way refugees see themselves seems to be extensively shaped by this view. They watch reports about refugees in the media and they seem to embrace the terminology to access support and services. The current study argues that refugees can claim agency and lead the change they need in their context if they are given the opportunity and safe space to articulate their views and draw on their potential. By doing so, humanitarian actors and policy makers will be in a better position to tailor their response. 
How can refugees exercise their agency in different spheres such as policy, media and academia?

In order to participate actively in different social and academic platforms, refugees will first need to know about their rights to do so; i.e. that their voices deserve to be heard without fear of prosecution by authorities in their place of refuge. Once they feel safe, they will be more likely to voice their views, concerns and aspirations; rather than having journalists, researchers and authority spokespersons speaking on their behalf and making assumptions and generalisations about their situations and voices. Having to deal with vulnerable individuals and groups, these representing organisations hold ethical responsibility for respecting confidentiality and protecting their privacy as refugees see appropriate. There needs to be sufficient support to help them make informed decisions about sharing their voices and the implications that might have on them.

Can you tell us more about why you chose to study the role of drama as a tool to restore agency?

I used drama in teaching English to Syrian children as it serves a liberating function'; it creates an 'affective space' where students engage emotionally and feel safe to express their 'voice', tell their narratives, and take risks with the target language. By giving voice to students, they gain their agency and it becomes possible to understand their needs, aspirations and the challenges which they face in their everyday life as refugees and which NGOs and governments require in order to plan their response policies. Moreover, drama acts as a 'revolution' which goes beyond changing classroom interactions to give rise to a new status quo.

The narratives in these projects vary from daily life scenarios to fairy tales. The main purpose was to provide a space for students to develop ideas using a familiar structure. Students and teachers had the opportunity to play roles based on fictional characters in fairy tales and personal experience in everyday scenarios. Interestingly, these improvised scenes capture some of their lived experiences in limbo. 


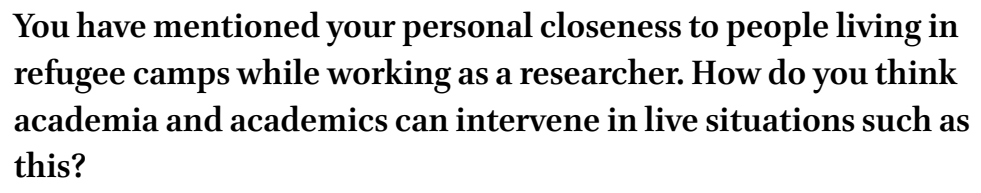
refugee camps while working as a researcher. How do you think academia and academics can intervene in live situations such as this?

Sharing home/war experience and understanding with research participants is key to establish trust so they open up with their opinions and so are likely to support the sustainability of the research in a security tight environment. As an academic, I carry a moral obligation to alleviate the suffering of the participants taking part in research through empowering them to learn transferrable skills and to develop a sense of autonomy through raising awareness and leading the change in improving their conditions. In order to respond to the scale of the crisis, it is important to embrace opportunities beyond research to meet urgent needs where possible. At the time that I was conducting my fieldwork, there were around half a million children out of school in Turkey alone. I tackled the question of access to education in different academic platforms, by arranging fundraisers to support displaced families and through getting involved in online teaching programmes such as Paper Airplanes. This has been an ongoing challenge.

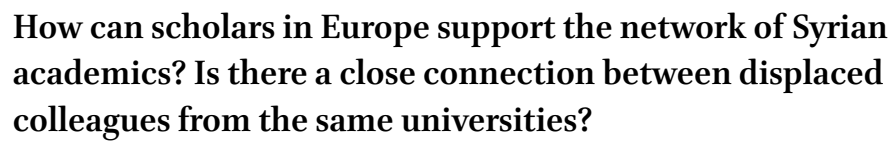

Academics pay a high price in war as they form the backbone of the educational life of their country. When they are forced to migrate, they leave a gap behind and they themselves will need support in the place they happen to move. Scholars from global academic institutions play a key role in keeping the academic life going through providing networking opportunities and resources to develop research in crisis situations. NGOs and charities such as CARA not only contribute to saving the lives of academics through funding opportunities and training programmes, but also to create an academic community where displaced academics connect and potentially consider projects to rebuild peace and save Syria's lost generation. 
9 Could you describe the conditions that impacted your research on the ground? Did you require further permits?

The unstable security situation was a major challenge to grapple with in accessing the border city Kilis: From the UквA questioning my intentions to cross the borders into Syria, to being considered a potential threat by the Turkish authorities who assumed I could be an MI6 spy. Refugee camps were also difficult to access and obtaining permission was a continuous process. Access was completely denied during elections and when clashes broke out near the borders. The liminal dynamics of the participants is illustrated by their moving between cities and camps and across the border to Syria and back, in addition to their virtual presence in different locations including Europe. This was a challenge in doing the project plan but also an opportunity to understand the context dynamics. I needed to obtain permission from the start to access the camp. Once I was inside, I had to obtain further permissions to access schools. I had to renew my visit to the camp every few days. It was almost impossible to do that, but with the help of the participants who were well connected with the camp authorities, I was able to extend my visit up to two weeks before I was asked to leave the camp. Again with the help of more participants, I was able to obtain a couple more access visits. My total visit lasted a month between coming in and going out.

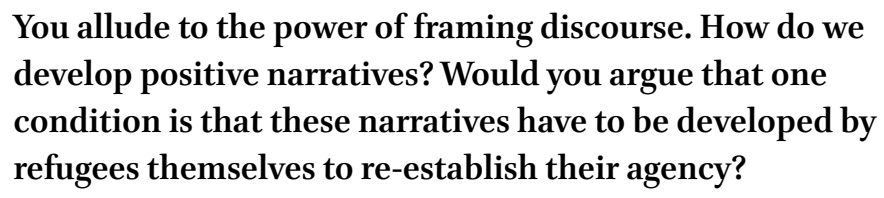

Discourse is very powerful in controlling the lives and movements of refugees. Policy makers use discourse to justify their political practices of assisting or demonising refugees. For some, refugees are victims who need our assistance; for others, they are coming to steal our jobs and destroy our economy. The media also takes part in reproducing such stereotypes when reporting 'selectively' about the refugee crisis to a larger audience. Refugees are in a disadvantaged position in both cases. This is because they lost their 'agency' in telling their stories and therefore others stepped in to provide a narrative. 
11 Refugee status, as you discuss, is necessary to receive essential support and regain agency - but it simultaneously reduces the agency of those claiming it. How do people overcome this dilemma?

By holding legal status as a refugee, displaced people acquire rights which are specified by UNHCR. However, in Turkey, Syrians hold 'temporary protection' status which gives them limited rights to access employment and other services. The emphasis on assistance, in fact, fosters a sense of dependency on the assistance provider. Refugees, on the other hand, have to act out the 'needy and worthy of assistance' role so they become eligible to receive support. In order to overcome this dilemma, it is important to build refugees' capacities to take part in assistance provision and ideally in leading their own initiatives.

\section{Where do you plan to take your research in the future?}

I am looking forward to taking my research into further applied sciences such as psychology and early childhood education as well as to the arts where it can help address the well-being of research participants. I also wish to be more involved in connecting with Syrian academics and other scholars in the field of refugee studies to share best practices and concentrate efforts to respond more efficiently to the crisis.

Interviewed by TJIS Editors

Mark Barclay and Paul Ostwald 